\title{
Recent Graduates' Perspective of Bachelors of Dental Surgery Program at KKU, College of Dentistry, Kingdom of Saudi Arabia: A Report
}

\author{
${ }^{1}$ Ibrahim Al-Shahrani, ${ }^{2}$ Rafi Ahmad Togoo, ${ }^{3}$ Sadatullah Syed
}

\begin{abstract}
This questionnaire survey of recent graduates was carried to find out the strengths and weaknesses of the undergraduate training program for dentists at the King Khalid University College of Dentistry (KKU/COD), Saudi Arabia. The questionnaire focussed on seven key areas of interest to a pioneer dental school, in a region where many patients are visiting the dentist for the first time. Almost all the graduates surveyed returned completed questionnaires ( $99 \%$ response rate). Study was conducted at the end of the internship year.

Respondents were generally satisfied with the quality of their training, skills acquired, the adequacy of tools of training (clinical and laboratory equipment). Training was also adjudged relevant and adequate for future practice as General Dental Practitioners. Most of the respondents planned to undergo postgraduate training in a dental specialty after the internship year. Two areas of weakness were cited by survey participants-inadequate patients and patient referral system, clinical support staff-related issues. Much more was expected of faculty and support staff than the program provided during their training.

It is hoped that findings of this survey will be considered along with other on-going evaluations of the KKU/COD program in the continuous improvement of the BDS training.
\end{abstract}

Keywords: Curriculum, Students' perceptions, Dental interns, Dental education, Dental program.

How to cite this article: Al-Shahrani I, Togoo RA, Syed S. Recent Graduates' Perspective of Bachelors of Dental Surgery Program at KKU, College of Dentistry, Saudi Arabia: A Report. World J Dent 2014;5(3):174-179.

Source of support: Nil

Conflict of interest: None

\section{INTRODUCTION}

The quality of training received by dental students can be greatly improved by several factors including regular feedbacks from all stakeholders of the program. Efforts to improve

\footnotetext{
${ }^{1,3}$ Assistant Professor, ${ }^{2}$ Associate Professor

1,2Department of Preventive Dental Sciences, Division of Orthodontics, King Khalid University, Abha, Kingdom of Saudi Arabia

${ }^{3}$ Department of Maxillofacial Surgery and Diagnostic Sciences King Khalid University, College of Dentistry, Abha, Kingdom of Saudi Arabia

Corresponding Author: Ibrahim Al-Shahrani, Assistant Professor, Department of Preventive Dental Sciences, Division of Orthodontics, King Khalid University, Abha, Kingdom of Saudi Arabia, e-mail: ishaahrani@gmail.com
}

dental training have usually been carried out by dental teachers, practitioners, employers of dental graduates, alumni and professional organizations. Few studies have focused on students impressions of their training. Until recently, inputs by the actual consumers of dental training have often been overlooked $^{1}$ for various reasons. Perhaps the most important explanation for this omission is the assumption that dental students may not be experienced enough to offer constructive ideas about their training. It has however been suggested that identifying areas of concern from the dental students' perspective can provide dental teachers and curriculum managers with much valuable information for program improvement. ${ }^{2}$ The American Dental Education Association (ADEA) obtains opinions about curricular content/emphasis (e.g. too much, too little, about right) from graduating seniors annually and communicates this information to schools. ${ }^{3-9}$

A Medline search encompassing the past two decades identified many interviews or survey-based studies for dental education that reported the perceptions and opinions of enrolled students or recent graduates about the process and structure of pre-doctoral education, program strengths and weaknesses, and adequacy of preparation for practice and/or recommendations for program modifications. These studies went beyond the typical course questionnaires employed to solicit student feedback about individual components of a curriculum. $^{2}$

Dental students' perspectives about their clinical training can be a major influence for change in how dentists are trained. A survey of North American dental students' views about their clinical training was conducted in 2003-2004. ${ }^{10}$ Twenty-one dental schools took part in this study. Results of the survey were to be used for the improvement of dental curricula in North American dental colleges. They also helped to highlight challenges in the development of a new cadre of clinical instructors to replace 'the boomer generation' of dental teachers as they approached retirement age. ${ }^{10}$

King Khalid University College of Dentistry (KKU/ COD) at Abha is the first under-graduate dental institution in the southern part of the Kingdom of Saudi Arabia. Established in 2003, KKU/COD graduated its pioneer set of dentists in July 2009. Since then, 217 dentists have graduated from this institute. 
There is a perceived need to prove to students, to the dental profession and to the public at large that students graduating from the college are well equipped to address the changing oral healthcare needs of the community. As part of the over-all evaluation of its dental program, KKU/ COD decided to conduct a questionnaire survey of its new graduates at the end of the dental internship year for batches 4, 5, 6 and 7 .

The primary goal of this survey was to identify areas of strengths and weakness in the undergraduate dental training program, as perceived by recent dental graduates of this college. Their views and suggestions should form part of the items for consideration in the continuous improvement of the BDS curriculum at KKU/COD.

\section{MATERIALS AND METHODS}

The research protocol used for this survey was reviewed and approved by the Ethics Committee of the KKU/COD. The survey questionnaire was distributed to one hundred and forty newly qualified graduates of the college toward the end of their internship year. One hundred and thirty eight (99\%) returned completed questionnaires. Data analysis consisted mainly in classifying interns' responses into the seven key areas itemized below to find out the strengths and weakness in the BDS program.

This survey focussed primarily on seven key areas, namely:

1. Adequacy of theoretical training and delivery methods.

2. Quality of clinical training and skills acquisition.

3. Adequacy of training resources.

4. Role of staff and availability of patients.

5. Quality assurance, infection control policy and implementation.

6. Internship research and interns' postgraduate aspirations

7. Community service.

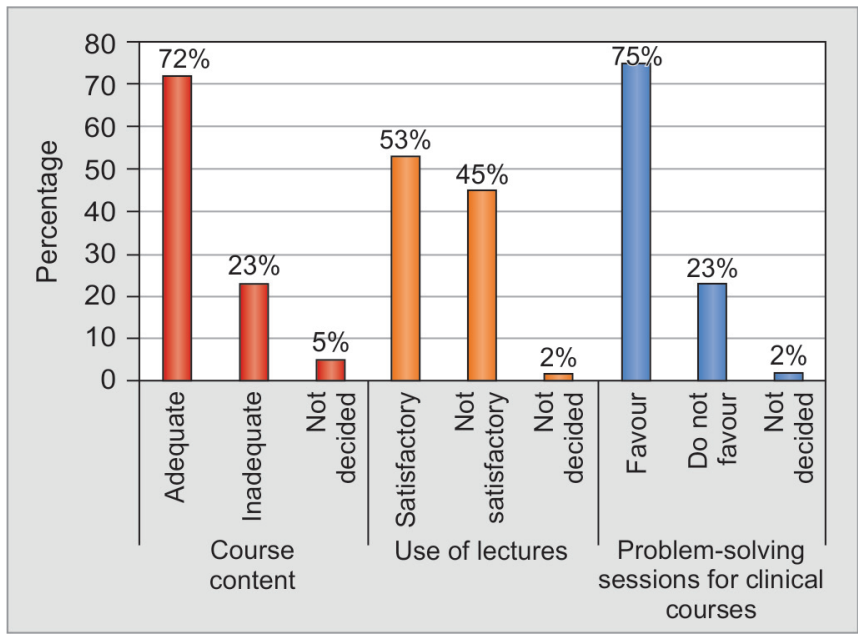

Graph 1: Curriculum design, use of didactic lectures and problem-solving sessions

\section{RESULTS}

Responses collected from respondents are grouped along the key areas covered by this study.

\section{Adequacy of Theoretical Training and Delivery Methods}

Participants responded to specific questions about program contents, delivery methods and training sessions. Response rate for each of these areas were $95 \%, 98 \%$ and $98 \%$ respectively (Graph 1). Seventy-two percent of interns believed the curriculum design and course contents were adequate and satisfactory in contrast to $23 \%$ who felt much more needed to be done in the stated areas. Concerning delivery methods of the program, the verdict was split, $53 \%$ interns agreed with the way lectures were used for their training and $45 \%$ disagreed. Only $6 \%$ strongly felt their lectures were not delivered in the best possible manner. For clinical courses, two-thirds (75\%) respondents favored the use of small-group problem-solving teaching method for such courses. In this category, 30\% strongly supported use of this teaching method.

\section{Quality of Clinical Training, Skills Acquisition}

Nine out of $10(86 \%)$ believed skills acquired in the BDS program were adequate for General Dental Practice (GDP) (Graph 2). Almost two thirds majority (64\%) felt clinical sessions were conducted in the best way possible. Time spent for clinical postings were adequate, according to $65 \%$ of respondents.

\section{Adequacy of Training Resources}

Adequacy of resources for undergraduate and internship training was considered quite important by all survey participants (Graph 3). Two thirds of interns (66\%) felt clinical

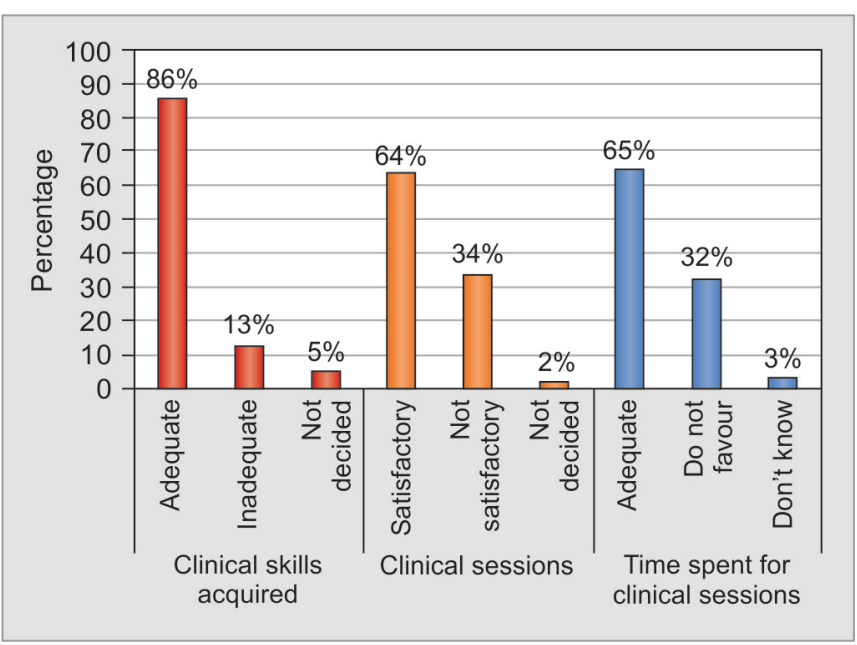

Graph 2: Clinical training and acquisition of skills related to GDP 


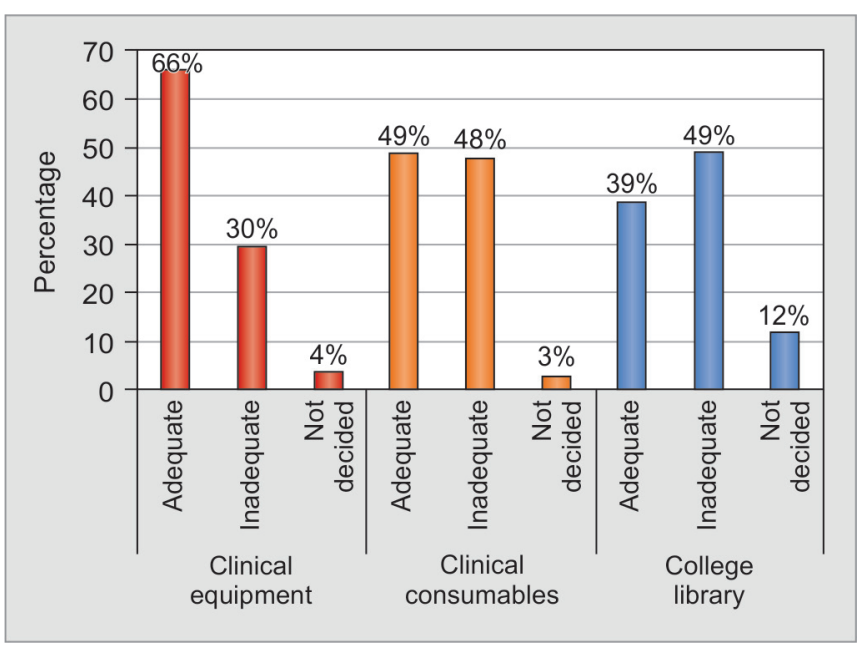

Graph 3: Training resources

equipments and instruments were adequate (quantity and, quality) whilst $30 \%$ felt otherwise. Concerning adequate provision of clinical consumables, opinion was equally divided (49\% agreed and 48\% disagreed) between those satisfied and the interns who disagreed. Responses related to corresponding library resources were quite similar. Only $39 \%$ of the Interns believed that college library resources were adequate.

\section{Role of Staff and Availability of Patients}

Respondents were not impressed with the service provided by the clinical support staff (Graph 4). Only 53\% agreed that the quality of the service provided was adequate in all courses and 44\% disagreed. In contrast to this two-third $(68 \%)$ believed the academic supervisors were helpful during clinical session. Less than half of the respondents $(45 \%)$ felt the number of patients available for training was enough and similar response (53\%) was observed for the patient referral system.

\section{Quality Assurance, Infection Control Policy and Implementation}

Almost seven out 10 respondents (69\%) saw the need for and were in full support of strict application of quality assurance procedures both in the clinics and support service areas (Graph 5). However, only a third (33\%) believed infection control violations were not taking place.

\section{Internship Research and Postgraduate Aspirations}

Eighty percent of interns had selected their research topics by themselves but less than half (45\%) felt resources for research were adequate (Graph 6). Majority of the respondents opted

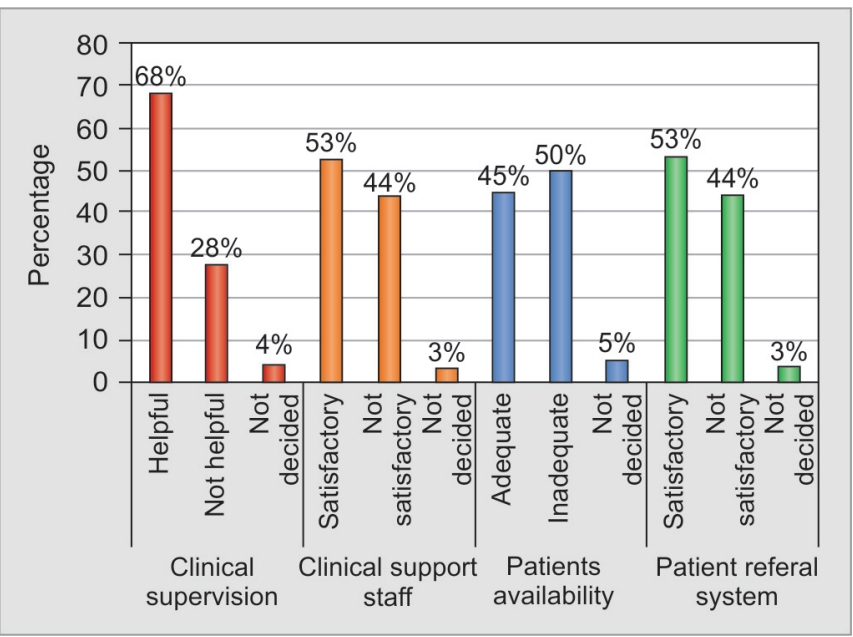

Graph 4: Staff services and patient referral system

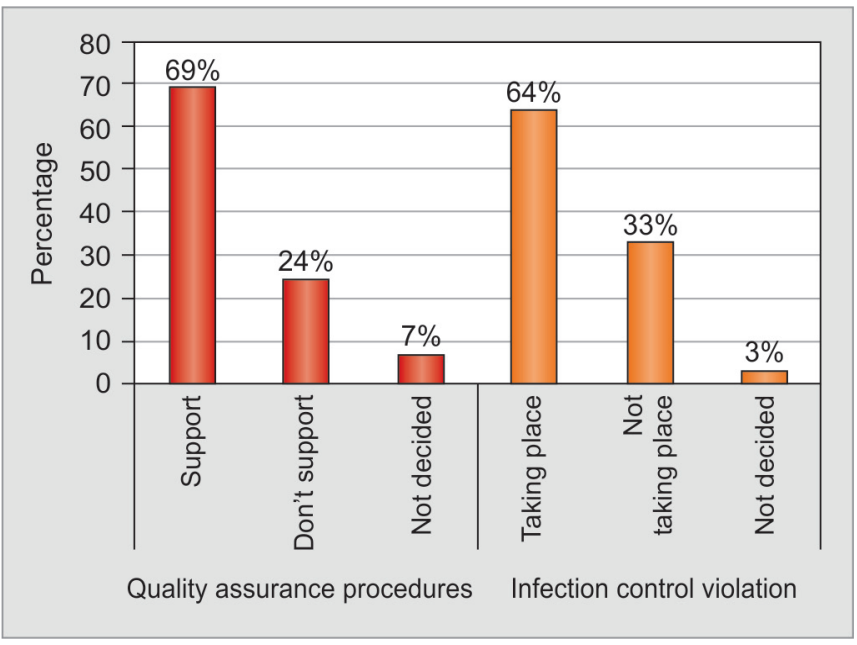

Graph 5: Quality assurance and infection control policies

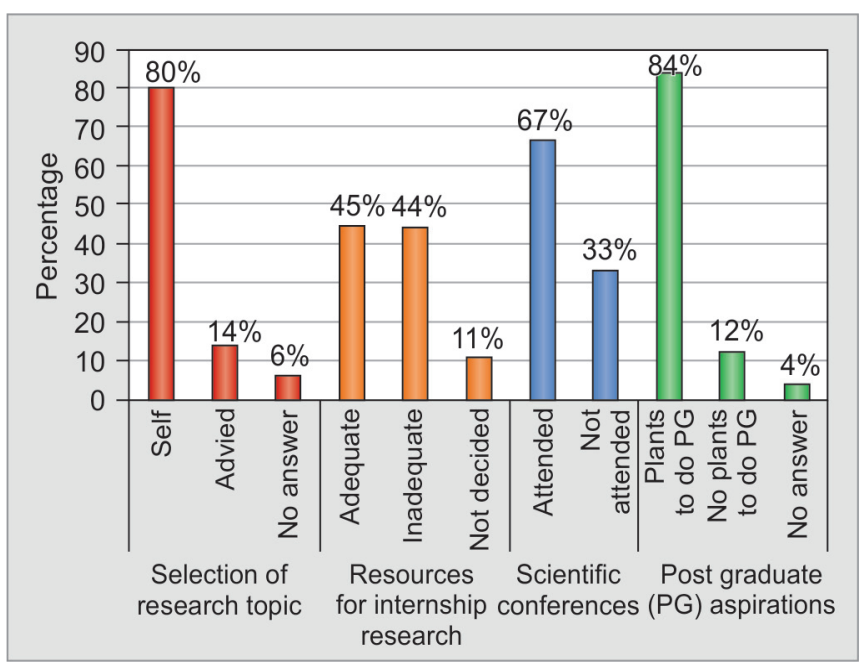

Graph 6: Internship research and postgraduate aspirations

for clinical research (62\%) while $24 \%$ preferred community, $12 \%$ laboratory based research and $2 \%$ did not answer the question. Nonetheless, $84 \%$ would wish to undergo postgraduate training in a dental specialty. Two-third of 
respondents $(67 \%)$ had attended dental scientific meetings during the course of training, but surprisingly only $53 \%$ believed they benefited from the meetings.

\section{Community Service}

Three quarters ( $76 \%$ ) felt community service was an important aspect of a dentist's training and should be made compulsory (Graph 7). Seventy-two percent agreed a full month during the internship year should be devoted to this experience. Sixty-six percent feel KKU Internship Community Service Program (ICSP) adequately fulfils the objectives of community service.

\section{DISCUSSION}

This survey was the very first of its kind at the KKU/COD. Respondents had never taken part in such a comprehensive review but were much impressed and eager to contribute to the improvement of the dental training program of their alma mater.

Dental students' perspectives about their clinical training can be a major influence for change in how dentists are trained. Holmes et al ${ }^{11}$ administered a survey instrument to recently graduated dental alumni of the University of Colorado School of Dentistry, USA. Their self-perception of competence at the time of graduation was evaluated in twenty-one selected areas. Graduates generally felt most competent in their ability to treat dental caries and the least competent in their ability to recognize myofascial pain and temporomandibular joint disorders. The survey also identified areas of strengths and weakness of their comprehensive care curriculum, as perceived by the graduating dentists. ${ }^{11}$

The questionnaire survey tool was similarly utilized by Polyzois et al ${ }^{12}$ to find out if there was an agreement between students and their supervisors on the quality of clinical teaching in Restorative Dentistry at the Dublin Dental School and Hospital. This study helped to identify differences on

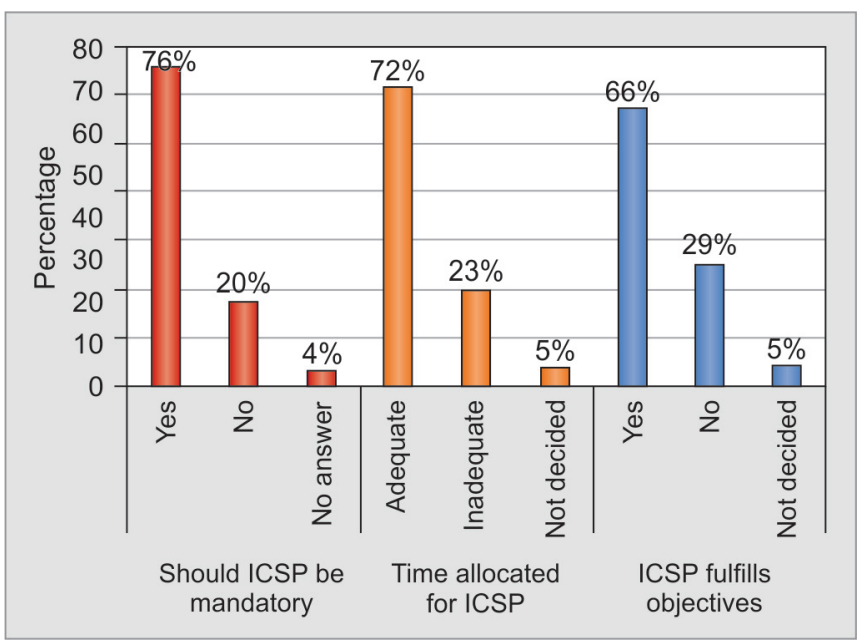

Graph 7: KKU internship community service program how effective clinical teaching was perceived between three academic years in addition to highlighting specific teaching behaviors that were most and least helpful in learning. ${ }^{12}$

The Association of Canadian Faculties of Dentistry developed a competency list which formed the basis of a survey of recent graduates and graduating class of the University of Toronto Faculty of Dentistry. ${ }^{13}$ This selfperceived competency survey also constituted part of a review of the Faculty's undergraduate curriculum to assess its relevance to general dental practice. The 'bread and butter' items of dentistry such as basic restorative dentistry, oral diagnosis and treatment planning as well as basic periodontology were covered in the study. ${ }^{13}$

ADEA obtains opinions about curricular content and emphasis (e.g. too much, too little, about right) from graduating seniors annually and communicates this information to schools. ${ }^{3-9}$ Chambers ${ }^{14}$ pointed out; there is an increased public and professional demand for accountability in education. This includes a need to prove to the students themselves, to the profession, and to the public at large that the students who graduate from the new curriculum are well equipped to address the changing oral healthcare needs of the community. ${ }^{14}$

The present study focussed largely on broad issues of concern to a pioneer dental school, in a region where many patients are visiting the dentist for the first time. Hence, it is important that the strengths and weaknesses of the new college are discovered early to enhance program quality. Dental students have little input into the selection of course topics and subject matter included in their training program. ${ }^{15}$ Curricular requirements and course contents are dictated by accreditation bodies, like the National Commission for Academic Accreditation and Assessment (NCAAA) in Saudi Arabia and the Council on Dental Accreditation (CODA) in the USA. This fact may account for respondents' mixed response for program contents, delivery methods and training sessions of the KKU/COD BDS program. The great popularity of small-group, problembased teaching method is in agreement with several studies which claim that active teaching approach is more effective than passive methods like the age-old, didactic lectures. ${ }^{16-20}$ Michel et $\mathrm{al}^{21}$ found in their research, evidence that active learning can lead to improved cognitive outcomes within a class. Biggs also concluded that problem-based learning is a successful teaching and learning strategy used to engage students in deep rather than surface learning and where the learning is student-focused rather than teacher-focused. ${ }^{22,23}$ In KKU/COD 'small group discussion' started with one oral surgery related course but during the course of this study more courses have included problem based learning in their teaching strategies. 
It is interesting to observe that respondents largely affirmed duration of training and the skills acquired during training were adequate for general dental practice whilst at the same time insisting faculty and support staff needed to do much more to enhance training of future graduates. Conflicting sentiments were expressed in regard to adequacy of clinical and laboratory resources for training: more needed to be done in the areas of dental consumables and resources for interns' clinics. In terms of availability of patients, less than half of respondents felt the number of patients available for training was adequate and a similar response was observed for patient referral system. Even before the results of this study were known inadequacy in this area of clinics were recognized by the administration. Efforts are ongoing to reorganize the clinics reception area and equip the medical records department. Recently, patient management system software ' $R-4$ ' has been acquired to assist patient filing and referral.

Although respondents overwhelmingly saw the need for and were in full support of strict application of quality assurance and infection control procedures both in the clinics and support service areas, only a third felt infection control violations were not taking place. A quality control unit has been set up with personnel having quality management skills in an effort to check such violations.

For reasons not explained by this study, almost 9 out 10 respondents would wish to undergo higher training in a dental specialty. This is in total contradiction to the primary purpose of the BDS program which is designed to train General Dental Practitioners! It is also not in agreement with similar studies carried out in the Middle East, Europe and America where new dental graduates generally opt for general dental practice. ${ }^{24-27}$ Could respondents' desire for postgraduate training and specialization be because they still see their teachers as role models? Or could their preference for specialist dental training simply be a reflection of respondents' dissatisfaction with prospects of the general dental practice arena, currently dominated by governmental ministries and agencies? Further studies are required to find out why vast majority of new dental graduates prefer not to go into general dental practice, as envisioned in their undergraduate training program. It is also important for future surveys to find out the attitudes of subsequent graduates toward taking general dental practice and community dentistry as professional careers. Monitoring trainees' attitudes to didactic lectures and reason/s for their attitudes should similarly be investigated in future surveys. Findings of such studies may well influence the goals and future direction of the BDS program.

\section{CONCLUSION}

Strengths and weaknesses of the BDS Program as perceived by new graduates of KKU/COD undergraduate dental program scored high approval rating in key areas of curriculum, clinical training, community service and trainee's acquisition of clinical skills. According to respondents, training in research methodology coupled with simple research projects by interns and the use of weekly, smallgroup, problem-solving sessions, can greatly enhance quality of the program.

The weaknesses cited by new graduates focussed on two key areas. The first was inadequate patients and poor patient referral system. The second area was faculty and staff-related issues. Much more was expected of faculty and clinical support staff than was provided during their training. This high expectation by trainees, including general dissatisfaction with clinical support staff, might have been due to the relative immaturity of trainees who probably expected to be 'spoon-fed' in most areas of their training.

It is hoped that findings of this survey will be considered along with other evaluations of the KKU/COD program in the continuous improvement of the BDS curriculum.

\section{REFERENCES}

1. Cardall WR, Rowan RC, Bay C. Dental education from the students' Perspective: curriculum and climate. J Dent Educ 2008;72(5):600-609.

2. Henzi D, Davis E, Jasinevicius R, Hendricson W, Cintron L, Isaacs M. Appraisal of the dental school learning environment: the students' view. J Dent Educ 2005;69(10):1137-1147.

3. Weaver RG, Haden NK, Valachovic RW. Annual ADEA survey of dental school seniors: 2002 graduating class. J Dent Educ 2002;66(12):1388-1404.

4. Weaver RG, Haden NK, Valachovic RW. Annual ADEA survey of dental school seniors: 2003 graduating class. J Dent Educ 2004;68(9):1004-1027.

5. Weaver RG, Chmar JE, Haden NK, Valachovic RW. Annual ADEA survey of dental school seniors: 2004 graduating class. J Dent Educ 2005;69(5):595-619.

6. Chmar JE, Weaver RG, Valachovic RW. Annual ADEA survey of dental school seniors: 2005 graduating glass. J Dent Educ 2006;70(3):315-339.

7. Chmar JE, Harlow AH, Weaver RG, Valachovic RW. Annual ADEA survey of dental school seniors, 2006 graduating class. J Dent Educ 2007;71(9):1228-1253.

8. Okwuje I, Anderson E, Valachovic RW. Annual ADEA survey of dental school seniors: 2008 graduating class. J Dent Educ 2009;73:1009-1032.

9. Okwuje I, Anderson E, Valachovic RW. Annual ADEA survey of dental school seniors: 2009 graduating class. J Dent Educ 2010;74:1024-1045.

10. Henzi D, Davis E, Jasinevicius R, Hendricson W. North American dental students' perspectives about their clinical education. J Dent Educ 2006;70(4):361-377.

11. Holmes DC, Diaz-Arnold AM, Williams VD. Alumni selfperception of competence at time of dental school graduation. J Dent Educ 1997;61(6):465-472.

12. Polyzois I, McLouglin J, Kelly A, Claffey N. Clinical teaching in restorative dentistry and the variation between students' and supervisors' perceptions of its effectiveness. Eur J Dent Educ 2010 May;14(2):92-98. 
13. Greenwood LF, Lewis DW, Burgess RC. How competent do our graduates feel? Canadian J Dent Educ 1998 Apr; 62(4):307-313.

14. Chambers M. Curriculum evaluation: an approach towards appraising a post-basic psychiatric nursing course. J Adv Nurs 1988; 13:330-309.

15. Henzi D, Davis E, Jasinevicius R, Hendricson W. In the students' own words: what are the strengths and weaknesses of the dental school curriculum? J Dent Educ 2007;71(5):632-645.

16. Dorestanni A. Is interactive learning superior to traditional lecturing in economics courses? Humanomics 2005;21(1/2):1-20.

17. Sarason Y, Banbury C. Active learning facilitated by using a game-show format or who does not want to be a millionaire? J Manag Educ 2004;28(4):509-519.

18. Benek-Rivera J, Matthews VE. Active learning with jeopardy: students ask the questions. J Management Edu 2004;28(1): 104-118.

19. Nadershahi NA, Bender DJ, Beck L, Lyon C, Blaseio A. An overview of case-based and problem-based learning methodologies for dental education. J Dent Educ 2013;77:1300-1305.

20. Bassir SH, Sadr-Eshkevari P, Amirikhorheh S, Karimbux NY. Problem-based learning in dental education: a systematic review of the literature. J Dent Educ 2014;78:98-109.
21. Michel N, Cater J, Varela O. Active versus passive teaching styles: an empirical study of student learning outcomes. Small Business Institute National Proceedings 2009;33:(1) Winter, pp. 55-67.

22. Biggs J. What the student does: teaching for enhanced learning. Higher education research and development 1999;18(1)57-75.

23. Biggs J. Teaching for quality learning at university. Buckingham, UK: The Society for Research into Higher Education and Open University Press, ISBN 0-335-21168-2 Open University Press. 2003

24. Baharvand M, Moghaddam EJ, Pouretemad H, Alavi K. Attitudes of Iranian dental students toward their future careers: an exploratory study. J Dent Educ 2011;75(11):1489-1495.

25. Gallagher JE, Patel R, Wilson NH. The emerging dental workforce: long-term career expectations and influences. A quantitative study of final year dental students' views on their long-term career from one London Dental School. BMC Oral Health 2009;23(9):35.

26. Gallagher JE, Clarke W, Wilson NH. The emerging dental workforce: short-term expectations of, and influences on dental students graduating from a London dental school in 2005. Prim Dent Care 2008;15(3):93-101.

27. Pepper C. Implementing problem based learning in a science faculty. The University of Western Australia. Issues in Educational Research 2008;18(1). 